\title{
SÍNTESE E CARACTERIZAÇÃO ELIPSOMÉTRICA DE VIDRO A BASE DE ESCÓRIA DE DISTRIBUIDOR*
}

\author{
Camila Ferreira da Silva ${ }^{1}$ \\ Elivelton Ferreira Alves ${ }^{2}$ \\ José Luiz Paralovo ${ }^{3}$ \\ Raphael Midea Cuccovia Vasconcelos Reis ${ }^{4}$ \\ Ésoly Madeleine Bento dos Santos ${ }^{5}$ \\ Ledson Martins Agripino ${ }^{6}$ \\ Lívia Lopes de Oliveira Goulart ${ }^{7}$ \\ Célio de Jesus Marcelo ${ }^{8}$ \\ Ingrid Russoni de Lima $^{9}$ \\ Ladário da Silva ${ }^{10}$
}

\section{Resumo}

O presente trabalho descreve a síntese de um vidro de constituição inovadora, elaborado com adição de escória de distribuidor em sua composição. Suas propriedades ópticas foram determinadas através da realização da caracterização elipsométrica. Em virtude da vasta gama de composições vítreas possíveis e visando o reaproveitamento de um coproduto siderúrgico, propõe-se a utilização de escória de distribuidor para a composição de um novo vidro. Efetuou-se a análise superficial via microscopia confocal. Posteriormente ao preparo da superfície, as propriedades ópticas foram obtidas através da medida dos parâmetros elipsométricos $\tan (\psi), \cos (\Delta)$ e por conseguinte a obtenção preliminar do índice de refração e do coeficiente de extinção.

Palavras-chave: Vidro; Escória; Elipsometria.

\section{SYNTHESIS AND ELLIPSOMETRIC CHARACTERIZATION OF GLASS BASED ON DISTRIBUTOR SLAG}

\section{Abstract}

This work reports the synthesis of new glass with distributor slag in composition. The optical properties were obtained by means of ellipsometric characterization. Due to the great amount of possible glass compositions, and considering the reuse of slag, it is considered the use of distributor slag to produce a new glass. Surface analysis was made using confocal microscopy. After the surface finishing, the ellipsometric parameters $\tan (\psi)$ and $\cos (\Delta)$ were measured and the preliminary optical properties, i.e., refraction index and extinction coefficient were obtained.

Keywords: Glass; Slag; Ellipsometry.

1 Engenheira Metalúrgica, Mestranda em Engenharia Metalúrgica, Programa de Pós-Graduação em Engenharia Metalúrgica (PPGEM), Escola de Engenharia Industrial Metalúrgica de Volta Redonda (EEIMVR), Universidade Federal Fluminense (UFF), Volta Redonda, RJ - Brasil.

2 Doutor em Química, Professor, Departamento de Química, Instituto de Ciências Exatas (ICEx), UFF, Volta Redonda, RJ-Brasil.

3 Químico, Instituto de Ciências Exatas (ICEX), UFF, Volta Redonda, RJ-Brasil.

4 Engenheiro de Materiais, Doutor em Ciência e Engenharia de Materiais, Professor, Departamento de Engenharia Metalúrgica, Escola de Engenharia Industrial Metalúrgica de Volta Redonda (EEIMVR), Universidade Federal Fluminense (UFF), Volta Redonda, RJ - Brasil.

5 Engenheira de Materiais, Doutora em Ciências, Professora, Departamento de Engenharia Metalúrgica, Escola de Engenharia Industrial Metalúrgica de Volta Redonda (EEIMVR), Universidade Federal Fluminense (UFF), Volta Redonda, RJ - Brasil.

6 Engenheiro Metalúrgico, Escola de Engenharia Industrial Metalúrgica de Volta Redonda (EEIMVR), Universidade Federal Fluminense (UFF), Volta Redonda, RJ - Brasil. 
7 Engenheira Metalúrgica, Mestranda em Engenharia Metalúrgica, Programa de Pós-Graduação em Engenharia Metalúrgica (PPGEM), Escola de Engenharia Industrial Metalúrgica de Volta Redonda (EEIMVR), Universidade Federal Fluminense (UFF), Volta Redonda, RJ - Brasil.

8 Técnico, Escola de Engenharia Industrial Metalúrgica de Volta Redonda (EEIMVR), Universidade Federal Fluminense (UFF), Volta Redonda, RJ - Brasil.

9 Dentista, Doutora em Patologia, Pós-Doutoranda - PNPD/CAPES, PPGEM, UFF, Volta Redonda, $R J-B r a s i l$

10 Físico, Doutor em Física, Professor, ICEx, PPGEM, UFF, Volta Redonda, RJ - Brasil. 


\section{INTRODUÇÃO}

Os vidros representam materiais de importância estratégica e devido suas propriedades ópticas, dielétricas e químicas variadas revelam uma gama de lacunas a serem exploradas a nível de estudos investigativos. As diversas possibilidades de aplicações como produto final também abrem perspectivas e necessidades de aprofundada investigação desses materiais. O presente trabalho promoveu projeto e síntese de um novo vidro, cuja composição química possui contribuição de escória de distribuidor. Além disso, efetua-se a determinação de propriedades ópticas, especificamente, o índice de refração $(n)$ e o coeficiente de extinção $(k)$.

Segundo Shelby [1], um vidro pode ser considerado um sólido sem estrutura definida e que não apresenta uma ordem de repetição a longo alcance. Além desta ausência de periodicidade estrutural, exibe também uma região de transição vítrea.

Ao contrário dos sólidos cristalinos, a solidificação de um vidro não acontece em uma dada temperatura, comumente chamada de temperatura de fusão $\left(T_{f}\right)$. $O$ vidro passa a se comportar como sólido numa faixa de temperaturas, onde o tempo foi insuficiente para a ocorrência de um relaxamento estrutural efetivo. A presença desta faixa caracteriza a transição vítrea, geralmente chamada de $\mathrm{T}_{\mathrm{g}}$ [2].

A indústria siderúrgica brasileira destaca-se entre as mais ativas do mundo, sendo o país o décimo segundo maior exportador de aço bruto em 2015 [3]. Deste modo, além de aço o Brasil também dispõe de grande quantidade de coprodutos e rejeitos associados a esta produção. Neste sentido a escória originada nos processos de produção do aço, presente nas etapas de redução do ferro gusa em alto forno, refino do aço em aciaria e lingotamento do aço a partir do distribuidor, surge como um coproduto com destinos já consolidados.

Em termos de reciclagem, o emprego mais comum de utilização da escória tange a engenharia e construção civil. Vislumbra-se então a possibilidade de inserir, entre outros componentes, a escória siderúrgica de distribuidor na composição de um vidro e investigar as propriedades através da elipsometria.

A investigação das propriedades ópticas pode ser feita através de medidas elipsométricas de um material. O elipsômetro realiza suas análises considerando 0 campo elétrico da luz, que é uma onda eletromagnética. A técnica permite além da determinação dos parâmetros elipsométricos $\tan (\Psi)$ e $\cos (\Delta)$, a obtenção do índice de refração $(n)$ e do coeficiente de extinção $(k)$. Segundo Hench [4] trata-se de uma técnica não destrutiva que permite a obtenção de propriedades ópticas ao efetuar uma análise das mudanças que ocorrem na polarização da luz incidente ao interagir com o material. Essa luz, linearmente ou elipticamente polarizada atinge a amostra e devido este contato tem a polarização modificada. Deste modo, existe uma diferença entre a polarização da luz do feixe incidente sobre a amostra e do feixe refletido pela amostra.

Fujiwara [5] descreve a equação fundamental da elipsometria conforme a Equação 1:

$$
\rho=\tan \psi \mathrm{e}^{\mathrm{i} \Delta}
$$

Onde $\rho$ representa o coeficiente de reflexão, $\tan (\Psi)$ corresponde a razão entre amplitudes das polarizações paralela e perpendicular ao plano de incidência e $\Delta$ é a diferença de fase entre as polarizações paralela e perpendicular ao plano de incidência [6]. Os parâmetros da equação são influenciados pelas constantes óticas (índice de refração $(n)$ e coeficiente de extinção $(k)$ ), pelo ângulo de incidência da polarização, pelo comprimento de onda e demais propriedades da amostra. 
O índice de refração representa a capacidade do material conseguir refratar a luz incidente, enquanto coeficiente de extinção diz respeito a capacidade de um material atenuar essa luz (o quanto a luz se extingue ao passar por dado material) respectivamente [6], sendo importantes propriedades óticas a serem investigadas em vidros.

Devido à sensibilidade da técnica, a rugosidade da superfície do material pode afetar e ou tornar necessária modelagem específica para a caracterização elipsométrica. Desta forma fez-se necessário avaliar a topografia da amostra na forma bruta. A microscopia confocal pode ser empregada para este fim uma vez que é uma técnica não destrutiva que permite a construção de imagens tridimensionais da topografia através da aquisição de imagens com alta resolução de seções ópticas [7].

\section{MATERIAIS E MÉTODOS}

Para a realização deste estudo obteve-se por fusão uma amostra vítrea com matriz de fosfato de sódio $(\mathrm{NaPO} 3)_{n}$, bórax $\left(\mathrm{Na}_{2} \mathrm{~B}_{4} \mathrm{O}_{7} \cdot 10 \mathrm{H}_{2} \mathrm{O}\right)$, pentóxido de nióbio $\left(\mathrm{Nb}_{2} \mathrm{O}_{5}\right)$ e escória de distribuidor na composição. A Figura 1 ilustra as etapas de obtenção da amostra desde seu projeto até sua síntese.

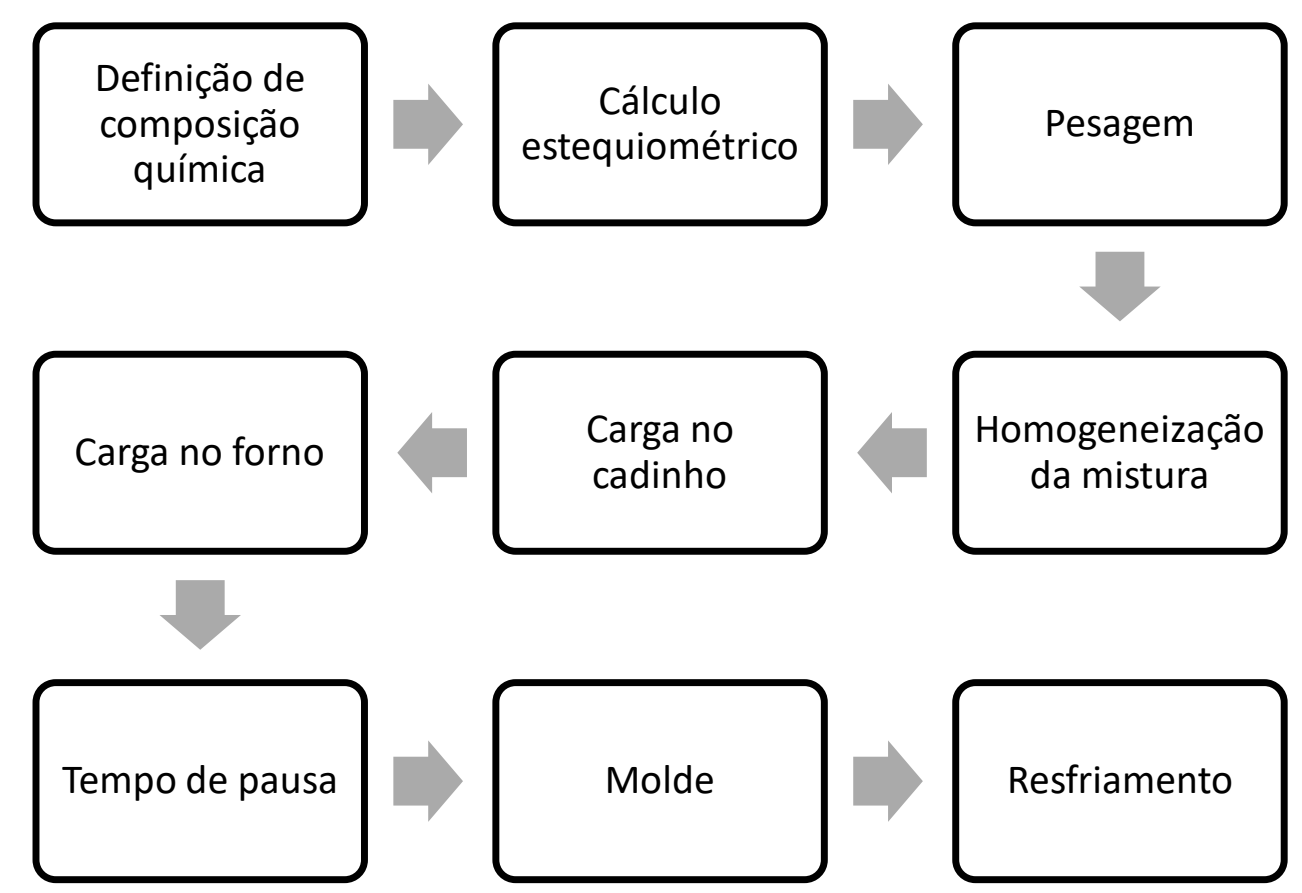

Figura 1. Fluxograma de metodologia da síntese do vidro.

Determinada a estequiometria, os reagentes foram pesados em balança digital de precisão (marca Weblabor, modelo M214Ai) e homogeneizados em almofariz. Preparada a mistura que daria origem a amostra, submeteu-se a fusão em cadinho de platina, em forno tipo mufla (marca QUIMIS, modelo Q318M24) por 60 minutos com temperatura em torno de $1200^{\circ} \mathrm{C}$ no Laboratório de Fundição da Escola de Engenharia Industrial Metalúrgica de Volta Redonda (UFF-EEIMVR). Ao final, o conteúdo do cadinho foi vertido em molde de aço inoxidável pré-aquecido e resfriado ao ar livre até atingir temperatura ambiente. A Figura 2 ilustra o forno utilizado. 


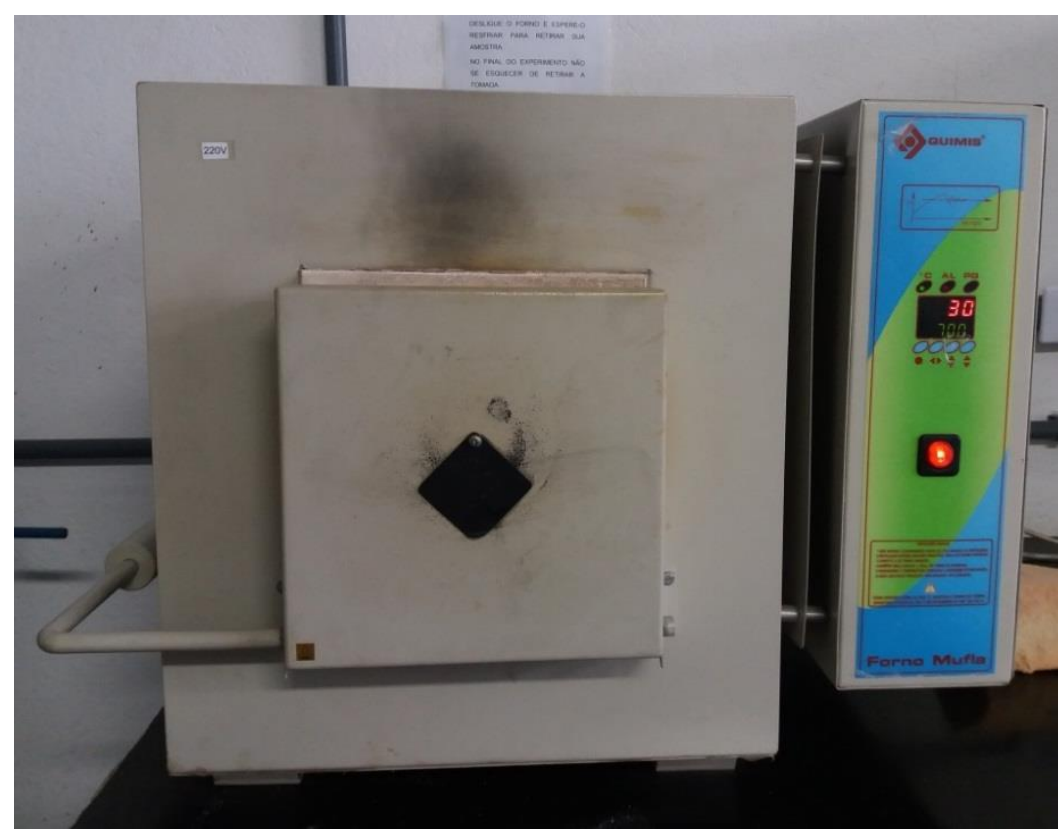

Figura 2. Forno mufla QUIMIS Q318M24.

Para avaliar a topografia da superfície da amostra em estado bruto, efetuou-se o levantamento topográfico da mesma. Para a análise utilizou-se o microscópio confocal (marca LEICA, modelo DCM 3D), mostrado na Figura 3 e disponível no Laboratório Multiusuários de Caracterização de Materiais (LMCM) do Instituto de Ciências Exatas da UFF, em Volta Redonda (ICEx-UFF VR).

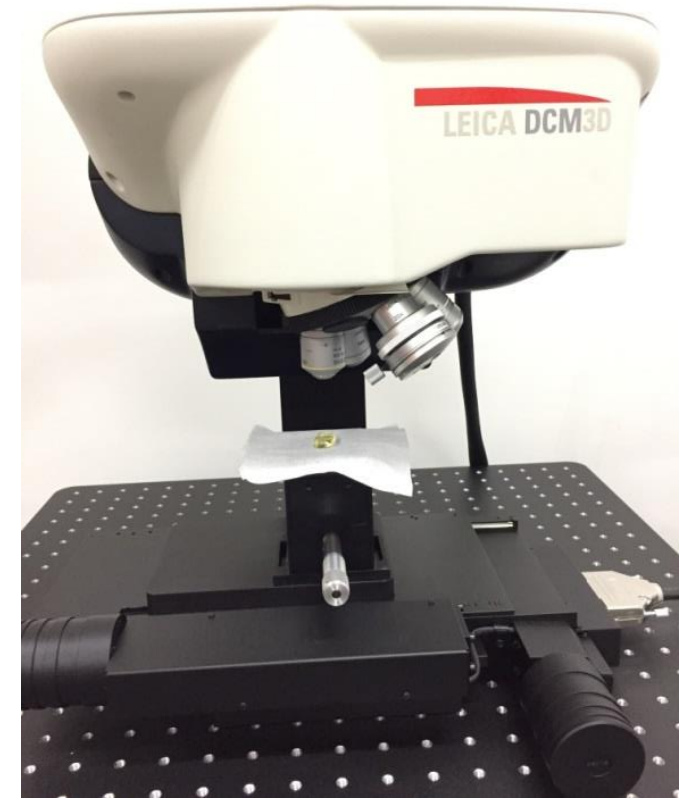

Figura 3. Microscópio confocal LEICA DCM 3D.

Visando então adequar a superfície da amostra para a realização das medidas elipsométricas, efetuou-se a preparação da mesma de forma a reduzir a rugosidade superficial que apresentava. Assim sendo, após sua síntese o vidro foi submetido a preparação da superfície através de lixamento com lixas de granulometria \#400, \#600, \#1200, \#1500, \#2000 e \#2500 seguido de polimento com pasta de diamante de $1 \mu \mathrm{m}$. 
Para a caracterização elipsométrica utilizou-se o elipsômetro espectrométrico de polarizador rotativo (marca SEMILAB, modelo GES 5S) disponível no LMCM do ICEx-UFF VR. A Figura 4 exibe o equipamento:

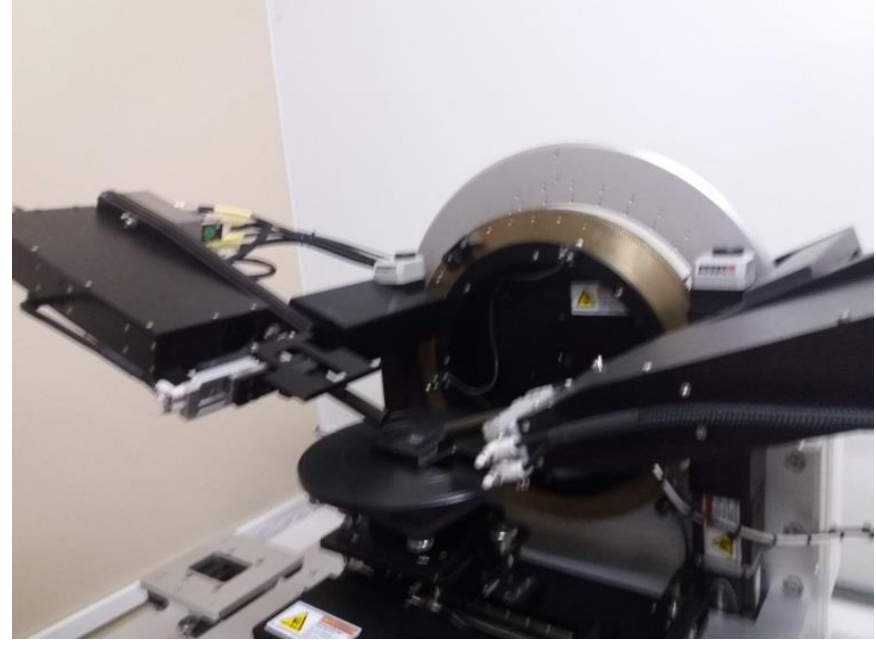

Figura 4. Elipsômetro GES $5 S$ da SEMILAB.

Com a superfície adequadamente preparada para a medida, os parâmetros elipsométricos tangente de $\psi$ e cosseno de $\Delta$ foram obtidos para cada comprimento de onda. Também se obteve as constantes ópticas $n$ e $k$. Todas as medidas foram angariadas sob um ângulo de incidência do feixe de $75^{\circ}$.

\section{RESULTADOS E DISCUSSÃO}

A fusão da composição proposta resultou em uma amostra vítrea com estabilidade química satisfatória. A mistura fundida apresentou alta viscosidade e após seu resfriamento, obteve-se o vidro exibido na Figura 5:

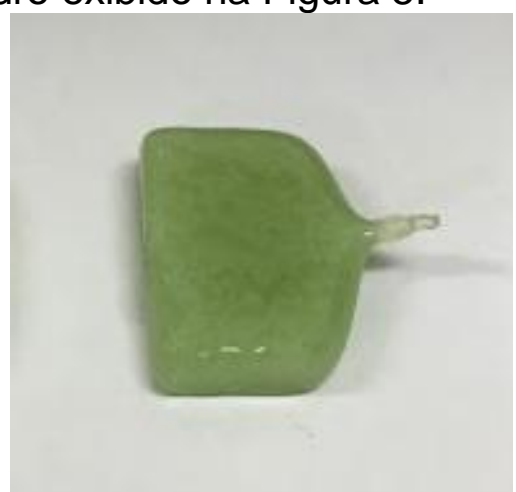

Figura 5. Vidro formulado com adição de escória de distribuidor.

Atribui-se a coloração verde a presença de óxido de ferro no vidro, oriundo da composição química da escória de distribuidor [8]. A Figura 6 mostra o resultado do levantamento da topografia da superfície da amostra, obtida em estado bruto. 


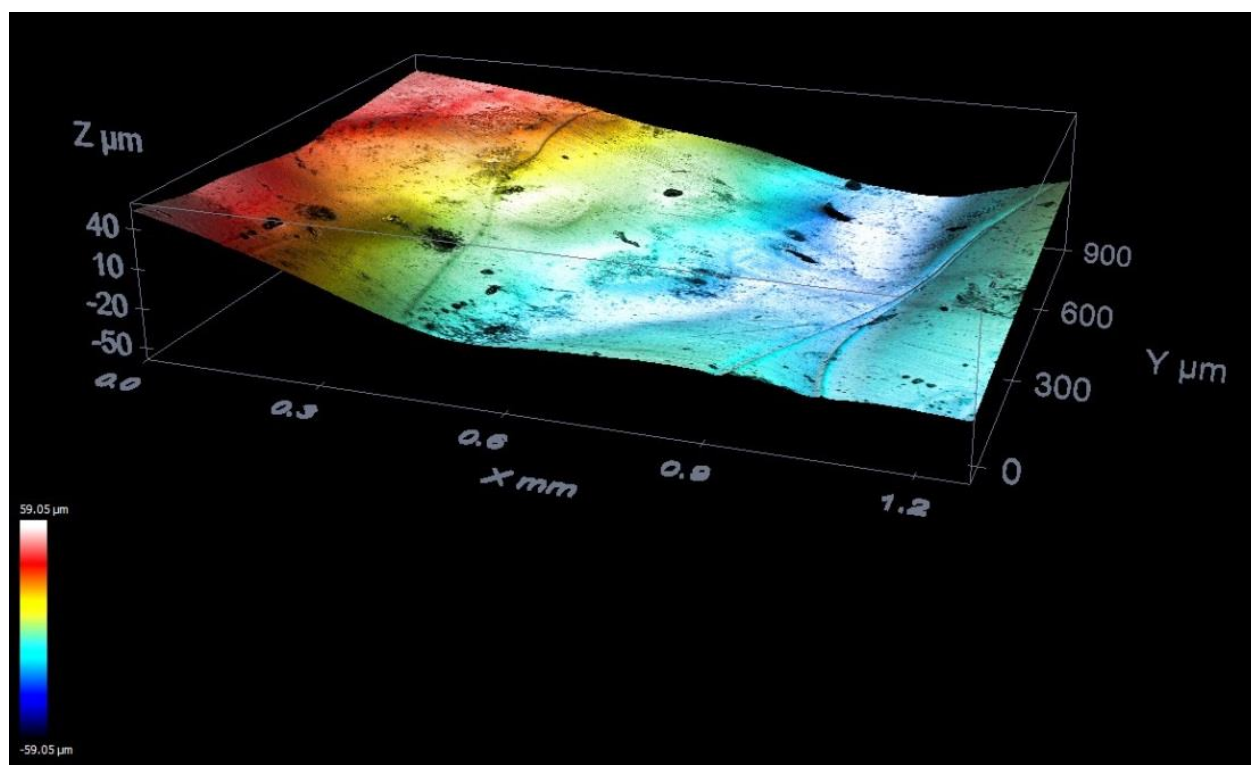

Figura 6. Levantamento topográfico do vidro de escória de distribuidor.

Nota-se que após o resfriamento, a amostra possuía uma superfície em estado bruto bastante irregular. Posteriormente a preparação superficial e a realização das medidas elipsométricas, foi possível determinar os parâmetros de $\tan (\psi)$ e $\cos (\Delta)$ referente a diversos comprimentos de onda. A Figura 7 e a Figura 8 ilustram os dados obtidos, preliminarmente, para $\tan (\psi)$ por comprimento de onda e $\cos (\Delta)$ por comprimento de onda, respectivamente.

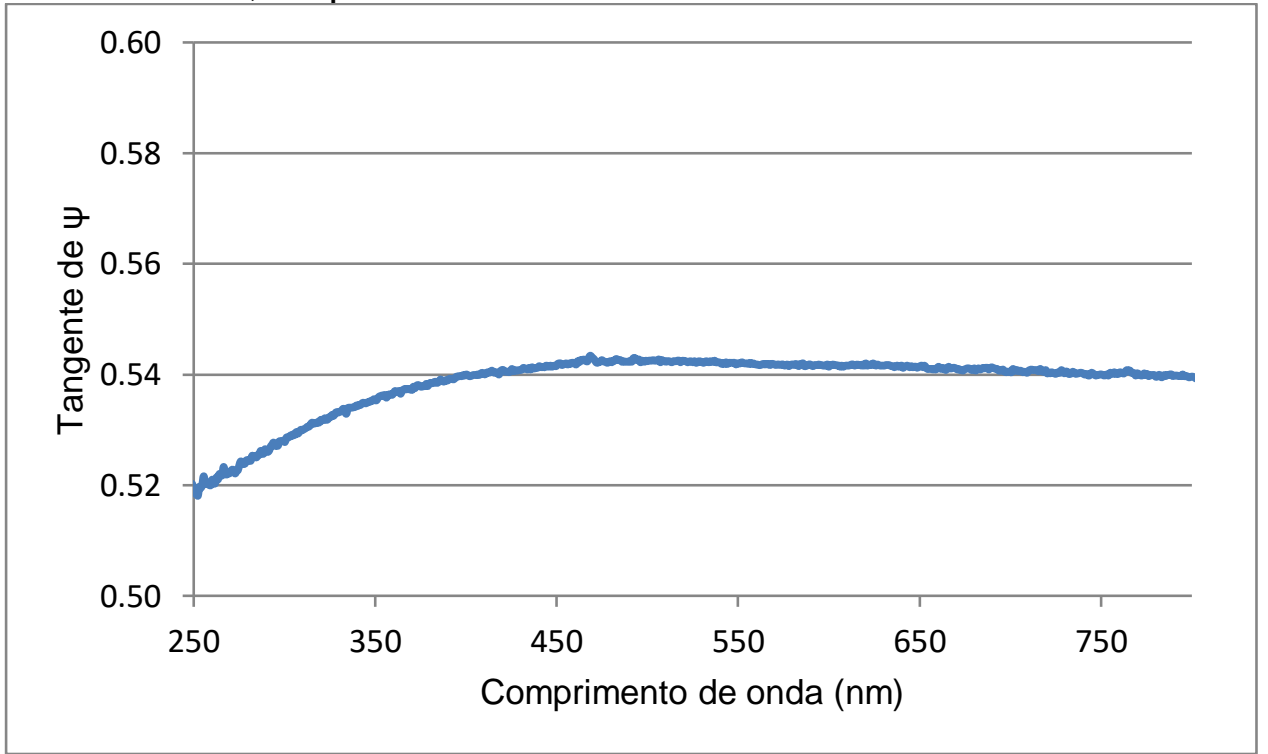

Figura 7. Tangente de $\psi$ versus Comprimento de onda. 


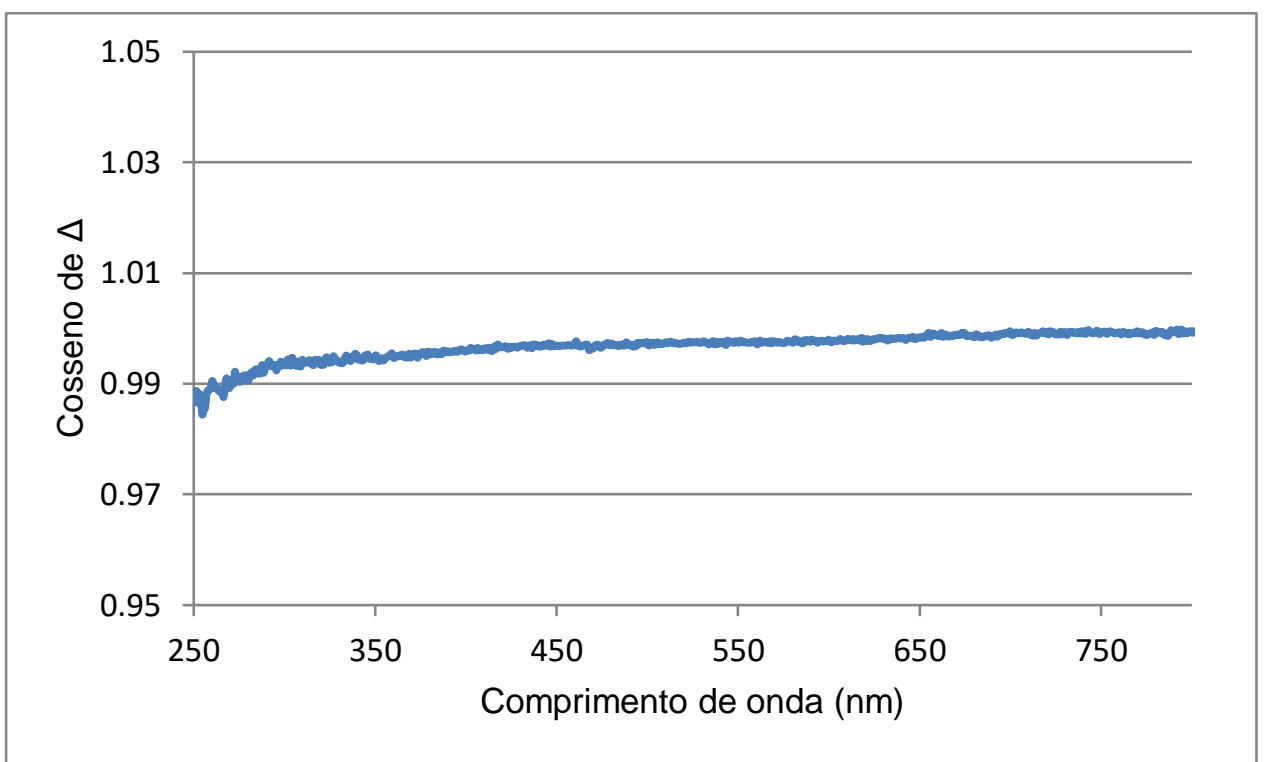

Figura 8. Cosseno de $\Delta$ versus Comprimento de onda.

A Figura 9 e a Figura 10 exibem os resultados obtidos para as constantes ópticas $n$ e k, referentes às propriedades óticas de refração e extinção da luz incidente.

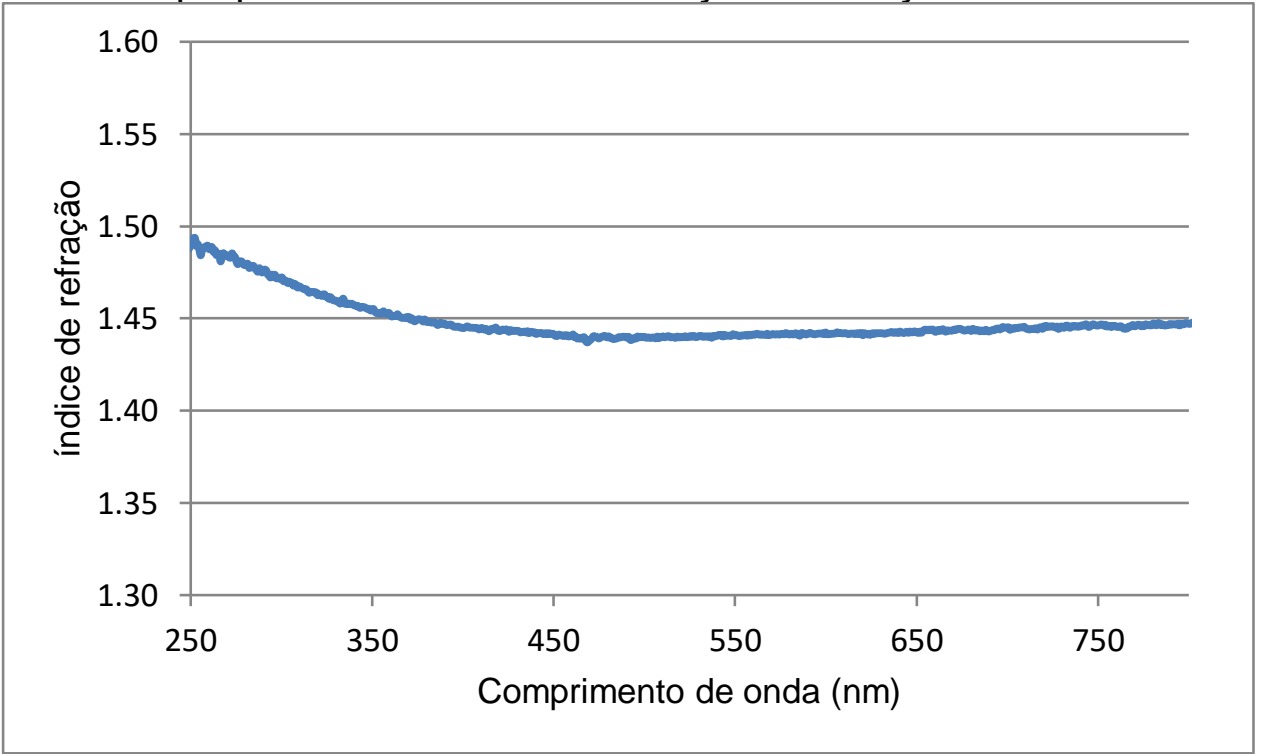

Figura 9. Índice de refração versus Comprimento de onda.

Os valores encontrados para índice de refração (n aproximadamente 1,5 ) vão de encontro aos valores encontrados para vidros de diversas composições na literatura [9]. 


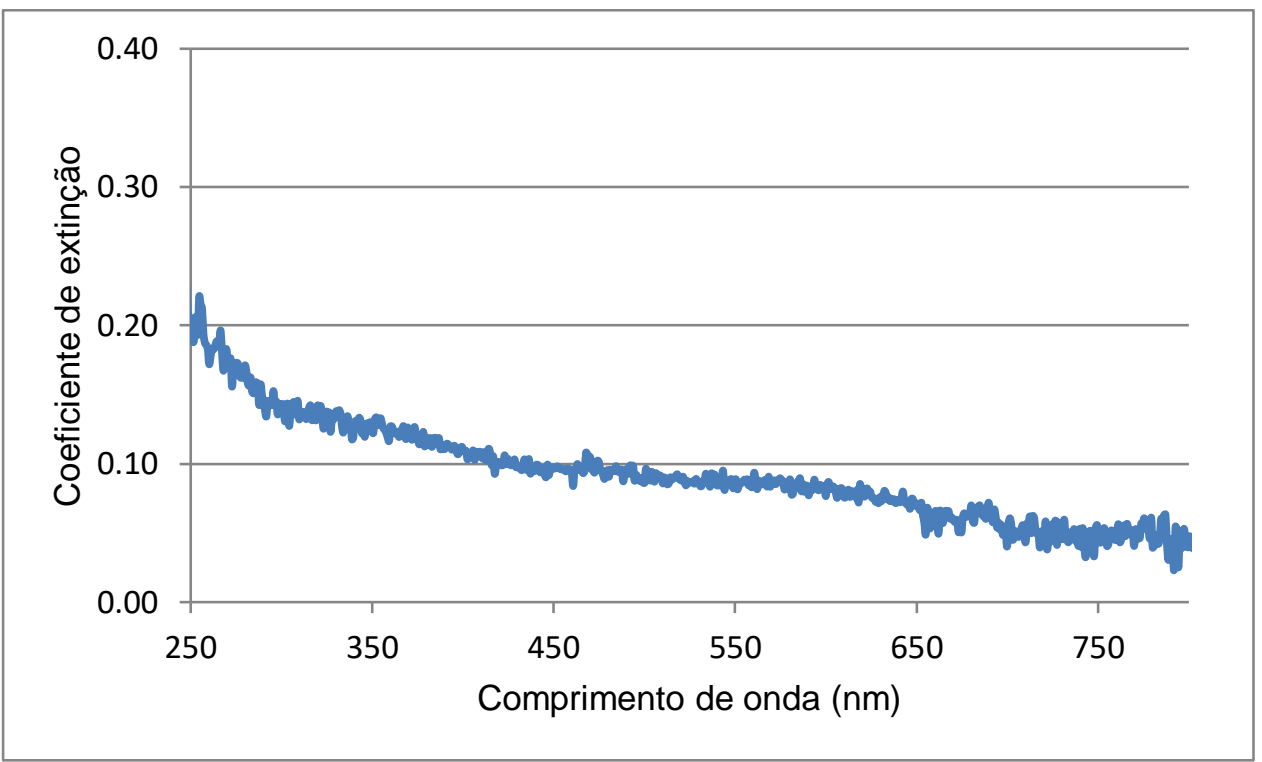

Figura 10. Coeficiente de extinção versus Comprimento de onda.

Iremos, em um segundo momento do estudo, realizar mais medidas elipsométricas e aprimorar as propriedades ópticas da amostra, modificando a proporção de compostos da composição química original.

\section{Agradecimentos}

Os autores agradecem às agências brasileiras: Fundação Carlos Chagas Filho de Amparo à Pesquisa do Estado do Rio de Janeiro (FAPERJ) - Projeto E26/110.321/2012, à Pró-Reitoria de Pesquisa, Pós-Graduação e Inovação (PROPPI) da Universidade Federal Fluminense (UFF) - Projeto 23069.004676/201497 pelo apoio financeiro e à FINEP pela compra do Elipsômetro Espectrométrico SEMILAB GES 5S e do Microscópio Confocal Interferométrico LEICA DCM3D.

\section{CONCLUSÃO}

Foi possível efetuar a síntese de um novo vidro, com adição de escória de distribuidor incorporada a sua composição. O material vítreo obtido apresentou estabilidade química, e coloração esverdeada em virtude da composição química diferenciada. O uso da técnica de elipsometria permitiu a obtenção preliminar das propriedades ópticas índice de refração e coeficiente de extinção. Iremos em seguida investigar a influência ocasionada por mudanças na composição nas propriedades ópticas do vidro, a fim de aperfeiçoar as características do mesmo.

\section{REFERÊNCIAS}

1 Shelby JE. Introduction to Glass Science and Technology. $2^{\circ}$ Edition. London: The Royal Society of Chemistry; 2005.

2 Alves OL; Gimenez IF; Mazali IO. Vidros. Cadernos Temáticos. Quim. Nova, 2001; Ed. Especial; 9-20.

3 World Steel Association. Major Importers And Exporters Of Steel 2015. [acesso em 10 jun. 2017]; Disponível em: https://www.worldsteel.org/en/dam/jcr:1568363d-f735-4c2ca1da-e5172d8341dd/World+Steel+in+Figures+2016.pdf

$4 \quad$ Hecht E. Optics. 4ํㅡㄹition. San Francisco: Addison Wesley; 2002. 
5 Fujiwara, H. Spectroscopic Ellipsometry: Principles and Applications. Japanese Edition, Tokyo: John Wiley \& Sons Ltd; 2003.

6 Garcia MTD, Couto JCM, Huguenin JAO, da Silva L; Caracterização de óleo em folhade-flandres por elipsometria. Anais do $70^{\circ}$ Congresso Anual ABM - Associação Brasileira de Metalurgia, Materiais e Mineração, 2015.

7 Samaniego R. Aplicaciones de la microscopia confocal. GH Continuada. 2009; 8(2): 115-119.

8 Martins TS; Isolani PC. Terras raras: aplicações industriais e biológicas. Quim. Nova, 2005; 28(1): 111-117.

9 Saggioro BZ. Caracterização de Superfícies de Vidros Expostas a Vapores de $\mathrm{KNO}_{3}$. Dissertação de Mestrado. Universidade Estadual Paulista. Rio Claro - SP, 2005. 